\title{
USING COMMUNICATION BOUNDARIES TO MINIMIZE ATHLETE SOCIAL MEDIA DISTRACTIONS DURING EVENTS
}

\author{
MICHELLE HAYES, *-_ KEVIN FILO,†-D CAROLINE RIOT,*_(D) \\ AND ANDREA N. GEURIN!- \\ *Department of Tourism, Sport and Hotel Management, Griffith University, Nathan, QLD, Australia \\ $\dagger$ Department of Tourism, Sport and Hotel Management, Griffith University, Southport, QLD, Australia \\ Institute for Sport Business, Loughborough University, London, UK
}

\begin{abstract}
Sport organizations regulate athletes' use of social media for many reasons including the protection of the organization's reputation. Several strategies have been introduced to minimize issues related to the negative consequences athlete social media use may present, yet whether these strategies also work to address social media distractions experienced by athletes during major sport events is not well known. Utilizing communication privacy management (CPM) theory, the purpose of the current research was to examine the aspects of social media that sport administrators perceive to be distracting to athletes and what support and management mechanisms are utilized to address such concerns during major sport events. Semistructured interviews $(N=7)$ with Australian national sport organization (NSO) administrators were conducted. Sport administrators reported several aspects of social media that are perceived to distract athletes including personal and performance criticism and a fixation with social media profiles. Social media could also be used to manage athlete temperament. As a result, organizations highlighted both proactive and reactive communication boundaries and mechanisms that could be used to address concerns including content restrictions, best practice case studies, engaging in conversations, and monitoring. Opportunities for sport practitioners are described including conducting consultation sessions with athletes to better understand their needs regarding their social media use.
\end{abstract}

Key words: Major sport events; National sport organizations; Social media; Communication privacy management; Distractions

Introduction

Australian sport policy has predominately focused on international sport achievements (Stewart et al., 2005). The focus on elite funding and a strategic approach to developing athletes for elite success represents a key policy agenda for many countries (Sotiriadou \& De Bosscher, 2018). With a large amount of money invested to ensure Australian athletes succeed at major international sport 
events, concerns have been raised about social media and how their use by athletes during events has the potential to pose a distraction and impact performance (David et al., 2018; Encel et al., 2017; Fynes-Clinton, 2012).

Australian athletes have experienced criticism from media outlets alluding to their use of social media during events, with some media personnel and sport managers labeling the platforms as a distraction from competing and a potential contributor to disappointing results (e.g., Fynes-Clinton, 2012). These incidents are not isolated to Australian athletes as researchers across a variety of contexts have identified that several aspects related to social media use can compromise athlete performances. For instance, social media use has been associated with a fear of missing out, whereby some athletes feel the need to constantly check the platforms to stay updated with information (Taylor et al., 2016), while late-night tweeting before a competition has been linked to lower performance rates among players in the National Basketball Association (NBA) (Jones et al., 2018). Athletes have also reported several elements of social media that they associate with distraction, including an obligation to respond to messages, influx of notifications, susceptibility to unwanted messages, branding pressures, competitor content, and frequency of use before an event (David et al., 2018; Encel et al., 2017; Hayes et al., 2020). These negative outcomes and potential distractions highlight a need for National Sport Organizations (NSOs) to address issues related to social media.

Researchers have identified several management mechanisms used to address problematic social media use. For example, policy, education, and monitoring have been adopted by organizations to protect their reputation (McAdow et al., 2017; Sanderson, 2011; Sanderson, Browning, \& Schmittel, 2015). Further, a review of major research streams in the fields of social media and sport management scholarship highlights the role of policy in the regulation of athlete's use of social media (Abeza et al., 2015). However, limited research examining the support and management mechanisms employed by NSOs to help minimize issues related to social media distractions exists, despite a call for research to investigate administrators' perceptions of social media as a distraction and how this is managed (Hayes et al., 2020). Therefore, an opportunity exists to investigate how sport administrators feel about the distractions inherent to social media.

The current research is guided by communication privacy management theory (CPM). CPM provides a framework for researchers to examine and identify how boundaries are coordinated between and among individuals (Petronio, 2002). By using CPM as a theoretical framework, the current research can develop an understanding of how sport organizations address social media distractions by implementing communication boundaries for athletes. Through semistructured interviews, the current research examines the aspects of social media sport administrators perceive to be distracting and what support and management mechanisms are utilized to address such concerns during major sport events. The findings contribute to CPM through the perspectives of sport administrators and contextually through the application of the theory to major sport events. Further, the findings of the current research inform several managerial implications. Specifically, sport administrators could bolster training programs based on the aspects of social media athletes find distracting. The following section introduces the theoretical framework and reviews literature pertaining to the potential impacts of social media use and the support and management mechanisms provided to athletes.

\section{Literature Review}

\section{Communication Privacy Management Theory}

Several researchers have examined how sport organizations manage athlete social media use (e.g., Sanderson \& Browning, 2013; Snyder, 2014). As a result, several theoretical frameworks have been utilized including framing theory, expectancy violations theory, and CPM. Framing has been used to examine how sport organizations manage athlete social media use, with a key focus on social media policies (e.g., Sanderson, Snyder, et al., 2015). Research that utilized framing in a sport context has demonstrated that governing institutions framed social media in the hands of athletes as risky (Sanderson, 2011). However, framing theory traditionally focuses on journalists' language in 
news stories. Framing occurs when media outlets or organizations emphasize a certain aspect of a story to promote specific interpretations (Entman, 1993). Given the applications of framing theory to media studies and the focus on journalist messaging, a different approach was sought for the current research.

Expectancy violations theory (EVT) (Burgoon, 1993) signified an additional framework that was considered for the current research. An expectation represents a consistent pattern of behavior that is predictable, which can be specific to an individual, context, and/or relationship. Burgoon (1993) noted that people employ expectations to characterize and frame their interactions with others. People also employ expectations to evaluate how they perceive interactions and subsequently behave. In the context of the current research, the interactions could be between sport administrators and athletes regarding social media use and behavior.

Based on the underpinnings of EVT, the theory would be better suited to a study that predominately focuses on interactions between sport administrators and athletes and how these interactions inform social media behaviors. However, as the current research is more focused on the content of management and support mechanisms designed to address distractions, and not the interactions between sport administrators and athletes specifically, another framework was sought.

CPM represents another key theory that has been used across existing research to understand how athlete social media use is managed. Specifically, CPM has been used to understand the social media boundaries sport organizations set to reduce any potential damage that can come from athlete misuse of the platforms (e.g., McAdow et al., 2017; Pulido et al., 2017; Sanderson, 2011; Sanderson, Browning, \& Schmittel, 2015). Sport communication scholars have highlighted that CPM can provide value to sport social media research, particularly investigation of the management of athletes' use of the platforms (Sanderson, 2013).

CPM provides a framework for researchers to investigate the ways individuals manage private information and posits that communication is a goal-oriented task (Child et al., 2009; Petronio, 1991). The theory "offers a privacy management system that identifies ways privacy boundaries are coordinated between and among individuals" (Petronio, 2002, p. 3). In addition, CPM theory can facilitate understanding of tension between and among individuals regarding their private information (Petronio, 2007).

Pulido et al. (2017) utilized CPM to examine privacy management strategies and the subsequent impacts on student-athletes' Twitter usage and behaviors. The authors concluded that privacy management strategies affected Twitter usage behaviors, such as frequency of use, minutes spent on the platform, and the types of content. The work of Pulido et al. (2017) suggests that communication boundaries, if implemented effectively, could impact athlete social media behaviors and in turn address social media distractions. CPM was considered a suitable framework for the current research for several reasons. First, the other theoretical frameworks considered in this section and their application to the purpose of the current research were limiting. Second, the framework was deemed suitable due to the adoption of CPM in similar research, and the suggestion that CPM can be applied to examine how sport organizations and athletes negotiate acceptable social media use (Sanderson, 2013).

CPM is underpinned by six propositions (Child et al., 2009). First, individuals believe their information only belongs to them. For instance, athletes who use social media may view their content solely as their own, and not a reflection of their affiliated NSO. Proposition two determines that people believe they should be the only person to control the flow of the information they reveal. Proposition three suggests people develop and use rules to protect their privacy based on what is important for them and to stay in control of the information. Applying the first three propositions to the current research, it may be important for NSOs to develop communication boundaries to protect their reputation, which might be damaged by criticisms of the organization's management of social media use if athletes experience poorer performance as a result of social media distractions. Further, NSO practices might be criticized if athletes are seen to focus more on social media than their performance during a major sport event. CPM theory reveals rules can impact both individual privacy and collective privacy boundaries. For instance, Sanderson (2011) 
argued that it is plausible for athletic departments to enforce social media policies that regulate or restrict information that is disclosed by athletes in public and private domains.

Proposition four focuses on granting others access to information. Specifically, this extension of privacy boundaries occurs when an individual discloses private information to another person. The information then enters collective ownership, whereby the recipient is made a co-owner and is expected to co-own the responsibilities of managing the information (Child et al., 2009). Proposition five states that the co-owners negotiate privacy rules for how the information is disseminated to other parties. Three main types of privacy rules are forwarded by CPM in line with proposition five including permeability, negotiations of ownership, and linkage rules. Permeability rules allow co-owners to determine how much third parties know about information. Meanwhile, negotiations of ownership rules are designed to determine how much control the co-owners have over the private information. Next, linkage rules are in place to consider and manage who else can know the information. Athletes may be required to sign a team agreement when representing a national team at a major sport event. The team agreement may include boundaries and restrictions on the content athletes post via social media or when the platforms can be used.

Finally, proposition six demonstrates the possibility of boundary turbulence due to a breakdown in communication between the co-owners of information (Child et al., 2009). This may be evident through athletes not adhering to a social media policy implemented by NSOs. Turbulence occurs when co-owners experience disruptions, violations, or unwanted mistakes when attempting to control and regulate the flow of information to third parties. In terms of the current research, NSOs may place information boundaries on athlete social media use during competition for a variety of reasons. In return, athletes may have differing opinions or be unaware that the information they post is potentially considered co-owned, which could lead to boundary turbulence and tension. There are several reasons sport administrators may develop communication boundaries for athletes such as protecting the reputation or brand of their organizations. However, boundaries may be enforced to address issues related to an athlete's performance. Few researchers have examined the role communication boundaries may have in minimizing distractions associated with social media. Instead, a small body of literature has explored the impacts social media may have on athlete performance.

\section{Social Media and Athlete Performance}

There are several benefits athletes can obtain through using social media during both event and non-event times including communicating and maintaining connections with their supporters, promoting themselves, and engaging with fans and followers (Geurin, 2017; Hambrick et al., 2010; Hayes et al., 2019). However, the platforms may provide athletes with additional stress (Rice et al., 2019). For instance, sport anxiety (i.e., a subclass of social anxiety) may be exacerbated by social media, while specific applications of the technology, such as push notifications, can cause concentration disruptions (Encel et al., 2017). Experiencing these disruptions may impact an athlete's mental preparation for an event, which may cause higher states of anxiety.

Zarei et al. (2018) suggested that a motivating factor for event attendance is the quality and reputation of teams and players. Therefore, athletes can become the target of bullying, racial abuse, and other unwanted commentary through an online presence (Farrington et al., 2014; Geurin, 2017), particularly if their performance does not meet expectations. Sanderson and Truax (2014) revealed that athletes are criticized by fans with messages manifesting belittlement, sarcasm, threats, and mocking. Social media may also provide an avenue for fans to direct sexist remarks toward athletes (Litchfield et al., 2016, 2018). Previous research has identified that athletes receive sexual comments, physical threats, and emotional ridicule (Geurin, 2017; Litchfield et al., 2016). Athletes may experience feelings of anxiousness in response to the potential criticisms they may receive if their upcoming performance does not meet expectations (David et al., 2018).

In addition to the commentary athletes receive through social media, researchers have begun to investigate how the use of the platforms may affect sleep patterns and athletic performance. In their examination of late-night Twitter use among NBA athletes, Jones et al. (2018) suggested that using 
the platform at abnormal hours can result in poorer performance the following day. The study observed lower performance results in specific measures such as shooting percentage for those athletes that engaged in late night Twitter activity.

This section identified the impacts social media have had on athletes. However, few researchers have examined the aspects of social media sport administrators perceive to be distracting to athletes. An opportunity exists to identify the aspects of social media that sport administrators perceive to be distracting to athletes during key competition times. As a result, the following research question is advanced:

Research Question 1: What aspects of social media (if any) do sport administrators perceive to distract athletes during major sport events?

Due to the potential negative consequences of social media use by athletes, some sport organizations have responded by setting time limits around usage while in competition (Pegoraro, 2010). Yet, additional mechanisms may be utilized by NSOs to enforce communication boundaries to address these concerns. These mechanisms can include social media training and are discussed in the following section.

\section{Management and Support Mechanisms}

Social media have exacerbated tensions between sport organizations and athletes (Sanderson \& Kassing, 2011). Researchers have examined several ways in which organizations can manage athlete social media use. These mechanisms include policy, monitoring, and education (McAdow et al., 2017; Sanderson \& Browning, 2013; Sanderson, Browning, \& Schmittel, 2015). Researchers have utilized CPM to gather an understanding of how social media communication boundaries are communicated to athletes, particularly through policy (e.g., McAdow et al., 2017). Policies have been adopted to govern how athletes use social media in certain situations including what constitutes appropriate and inappropriate content (Sanderson \& Kassing, 2011). For some organizations, social media policies are built into contracts to ensure athletes abide by such guidelines (Gabison, 2017).
Policy may be an effective technique used to restrict how often athletes use social media during events. Researchers have identified that social media policies intend to primarily decrease the potential negative outcomes of athletes using social media, such as offensive content damaging the reputation of organizations (McAdow et al., 2017). Notably, athletes have expressed their apprehension towards complete social media bans (Snyder, 2014).

To ensure policies are followed, sport organizations have turned to social media monitoring, which allows administrators to observe the content athletes post. Although research has established monitoring as a means to ensure athletes follow policy (Sanderson \& Browning, 2013), monitoring may provide sport organizations with an opportunity to determine how frequently athletes are using the platforms during major sport events, and whether this could become a distraction. However, there have been some criticisms of social media monitoring as it is seen as reactive rather than proactive (Sanderson \& Browning, 2013). Therefore, some organizations have opted for social media education to mitigate any negative consequences associated with athletes' use of social media (Sanderson, Browning, \& Schmittel, 2015).

Social media education has addressed the growing presence of social media. Nonetheless, a lack of effective education was highlighted by Geurin (2017), who examined female athletes' perceptions of new media. Sanderson, Browning, and Schmittel (2015) suggested that training should be aligned with athlete social media habits and inputs as it could potentially stimulate more responsible usage. Effective education programs could also potentially minimize the risk of athletes experiencing negative social media distractions during major sport events.

In addition to these formal mechanisms implemented by sport organizations, Gould et al. (2019) indicated that social media and mobile phone use has become a challenge for coaches, and as a result, sport organizations have begun to emphasize setting expectations around use, particularly for younger athletes who are viewed as preoccupied with mobile phones and social media. McAdow et al. (2017) acknowledged that multiple strategies or mechanisms that teach responsible social media use can relieve tensions between athletes and organizations in response to restrictions of 
communication. However, few researchers have examined whether these mechanisms are utilized to communicate existing boundaries related to social media and minimize distractions. As a result, a second research question is advanced:

Research Question 2: What communication boundaries are utilized by NSOs to address (or attempt to address) social media distractions during major sport events?

\section{Methodology}

\section{Participants}

Sport administrators working within Australian NSOs were invited to participate in a semistructured interview. NSOs provide athletes with national representation and are responsible for various aspects of the management of their sport including the development of the sport and selecting teams for international events such as the Olympic Games (Farmer \& Arnaudon, 1996). Thus, sport administrators working within these organizations were deemed as a suitable population for the current research. Further, several researchers have called for more research involving the perspectives of administrators regarding management and support mechanisms for athlete social media use, including those that have examined athlete perspectives of management and support mechanisms (e.g., Hayes et al., 2020; Sanderson, Browning, \& Schmittel, 2015; Snyder, 2014). For example, Sanderson, Browning, and Schmittel (2015) explored athlete perceptions of social media education but called for research to pursue the perceptions of those delivering social media education (i.e., administrators and coaches), to identify what characteristics they deem important. Similarly, McAdow et al. (2017) suggested a range of additional perspectives including athletic administrators, coaches, and compliance officers. Based on the recommendations of previous research, the current research sought to include administrator and coach perspectives. However, access to coaches presented a pragmatic constraint to the current research, in that they were either unable to engage with the research amidst their busy schedules or were not willing to participate (Suri, 2011).
Semistructured interviews allowed for the gathering of more in-depth information in relation to participant viewpoints and experiences of managing athlete social media use (Horton et al., 2004). The semistructured interview approach allowed for some flexibility in the questioning so the researcher could follow up on certain comments made by participants to further discuss how communication boundaries and management mechanisms may assist in minimizing social media distractions to athletes.

The lead researcher contacted 48 Australian NSOs seeking the most appropriate or most knowledgeable person on the topic area. The criteria included working within a relevant department area (e.g., media and communications or high performance or team management), and whether the administrators had a role in the development or delivery of support and management mechanisms related to social media. Seven administrators $(N=$ 7) agreed to participate in an interview; however, eight organizations were discussed, as one participant had held the same role at two NSOs within 1 year and explained her experiences with both organizations.

Once data saturation had been reached, no further interviews were scheduled (Gratton \& Jones, 2004). Data saturation was defined as the point at which no new information was being obtained. This occurred after seven interviews were conducted. Preliminary analysis took place after each interview to determine the saturation point. This enabled saturation to become clear after seven interviews. Similar research has also reached saturation points with relatively small sample numbers. For example, McAdow et al. (2017) conducted semistructured interviews with six communication professionals on the topic of student-athlete social media management within university athletic departments.

Five female and two male administrators participated in an interview. The age of participants varied between 25 and 44 . Four administrators worked in roles related to media, communications, and/or public relations. The remaining three administrators worked within the high-performance area of their organization. As requested by participants, the NSOs involved in the current research are not named and pseudonyms are used to protect 
Table 1

Interviewee Demographics $(N=7)$

\begin{tabular}{llcll}
\hline Interview & Pseudonym & Age & Gender & Organization Department \\
\hline 1 & Irene & $25-34$ & Female & Media and communications \\
2 & Nancy & $25-34$ & Female & Media and communications \\
3 & Nellie & $35-44$ & Female & Media and communications \\
4 & Harry & $25-34$ & Male & Media and communications \\
5 & Rose & $25-34$ & Female & High performance \\
6 & Giselle & $35-44$ & Female & High performance \\
7 & Wayne & $25-34$ & Male & High performance \\
\hline
\end{tabular}

participant identities. A summary of participant demographics is presented in Table 1 .

\section{Materials}

An interview guide was developed containing a list of 21 questions. Questions were grouped into three categories: (1) demographic information, (2) attitudes toward social media distractions, and (3) support and management mechanisms based on CPM and gaps identified in the literature. The gaps identified in the literature included the lack of research on support and management mechanisms utilized to address other issues of social media use apart from protecting the reputation of sport organizations. Another gap included the lack of administrator perspectives on managing social media challenges. First, demographic questions included age, gender, sport, years of experience in their role, and job title and department within the organization. Second, a set of questions focused on the participants' perceptions of social media as a potential distraction for athletes. A general question was posed to participants asking whether they perceived social media to be distracting for athletes competing at major sport events. For example, "Do you perceive social media as a distraction for athletes when competing at major sport events? Why/ Why not?"

The third group of questions switched the focus to the support and mechanisms employed by sport organizations to minimize distractions or other issues related to social media. The questions were based on three support and management mechanisms identified in the literature including social media policies, education, and monitoring (Sanderson \& Browning, 2013; Sanderson, Browning,
\& Schmittel, 2015; Snyder, 2014). Participants were asked if they utilized these mechanisms and were asked to explain why they utilized or did not utilize certain mechanisms. For example, several researchers have examined the utilization of policies to direct athletes on appropriate and inappropriate use (e.g., McAdow et al., 2017; Sanderson, 2011). Therefore, a broad question included "Does your sport have a social media policy to guide athletes? Why/why not?" Research has predominately focused on the content of such policies (e.g., Sanderson, 2011), with information lacking on how organizations respond to breaches, particularly around those that concern distractions. To address this gap, participants were asked whether they perceive a social media policy to be effective and how the organization responds if/when it is breached by an athlete, and whether they have any examples of incidents that occurred.

Similar questions were posed regarding social media training and monitoring. Of the few studies that have investigated social media education, Sanderson, Browning, and Schmittel (2015) noted that athletes perceived education to be compliance driven, admonishing and ambiguous, and lacking follow up. Geurin (2017) also noted the importance of providing education regarding branding efforts for athletes. However, little attention has been given to how social media distractions are addressed through education. Therefore, several questions were posed to administrators focusing on the perceived effectiveness, the content of education, and how and when the education is conducted. Examples include "How do you perceive social media education in terms of effectiveness (e.g., does it assist athletes in minimizing social media distractions?) Why/Why not?", "Can you please provide 
an example of how you/your sport educates athletes on appropriate social media use?", and "Are your athletes provided with social media education before a major sport event? Why/Why not?"

Researchers have highlighted the use of social media monitoring being conducted in line with policies (e.g., Sanderson \& Browning, 2013; Sanderson, Snyder, et al., 2015). However, this research has focused on monitoring to identify inappropriate content. Gould et al. (2019) indicated sport organizations have begun to emphasize setting expectations around use among athletes to address problems, and use monitoring to ensure that athletes are meeting these expectations. Therefore, interview questions were created to draw out whether monitoring is used for other purposes, such as addressing distractions. An example question includes "Do you or someone within your organization monitor your athletes' social media accounts? Why/Why not?" The complete interview guide is provided in the Appendix.

\section{Procedures}

After receiving ethical clearance from the lead researcher's institution, participants were recruited via purposeful and convenience sampling techniques (Etikan et al., 2016). Although convenience sampling comes with limitations, the pragmatic constraints of accessing sport administrators (e.g., availability) prohibited the authors from using other sampling procedures (Suri, 2011). Participants were recruited through publicly listed e-mail addresses on NSO websites. The e-mail contained a personal introduction, an overview of the research topic, and an option for the invitee to suggest other or more appropriate organizational members to participate in the research to ensure the interviews would gather sufficient data. Interviews were conducted between July and October 2018. The interviews lasted up to $45 \mathrm{~min}$. Interviews were conducted via telephone $(n=4)$ and face-to-face $(n=3)$ based on the availability and location of participants.

Interviews were voice recorded, and recordings were sent to an external company for transcription to ensure the accuracy and timely completion of transcripts. An incentive of a gift card draw with two prizes on offer was used to encourage prospective participants to partake in the interview (Singer
\& Ye, 2013). First prize was a gift card valued at $\$ 100$, and second prize was a gift card valued at $\$ 50$.

\section{Data Analysis}

Although the sample was small, a minimum of seven in-depth interviews is an appropriate number to conduct thematic analysis (Braun et al., 2016), thus making it possible to conduct thematic analysis on the current sample. Thematic analysis was employed to analyze the seven interview transcripts, as the technique is a "method for identifying, analyzing and reporting patterns (themes) within data" (Braun \& Clarke, 2006, p. 79). The analysis technique provides a tool for sport researchers to examine people's behaviors and their views on a specific issue or phenomena. The lead researcher engaged in the following six phases as suggested by Braun and Clarke (2006): (1) familiarization with the data, (2) generating initial codes, (3) searching for themes, (4) reviewing themes, (5) defining and naming themes, and (6) producing the report. Preliminary analysis was conducted after each interview to determine when saturation had been reached.

Data were analyzed manually using Microsoft Word documents and a Microsoft Excel spreadsheet. The lead researcher read through each transcript multiple times to familiarize themselves with the data (phase 1). Repeatedly reading the transcripts also allowed the researchers to confirm that saturation had been reached. Repeatedly reading the transcripts was conducted through the lens of CPM, which assisted in generating initial codes and identifying interesting features of the data (phase 2) related to the research questions. Data extracts were imported to an Excel spreadsheet along with the initial codes. Once all data and initial codes were entered into the spreadsheet, the sorting function of Microsoft Excel was used to group the same codes together. Once the initial codes and potential themes were identified, they were sorted with corresponding transcript extracts from interviewees. Once the themes were finalized, they were defined, before a review for any overlap was conducted (phases 3-5). Eight themes were revealed. These themes consisted of personal and performance criticism, fixation with their 


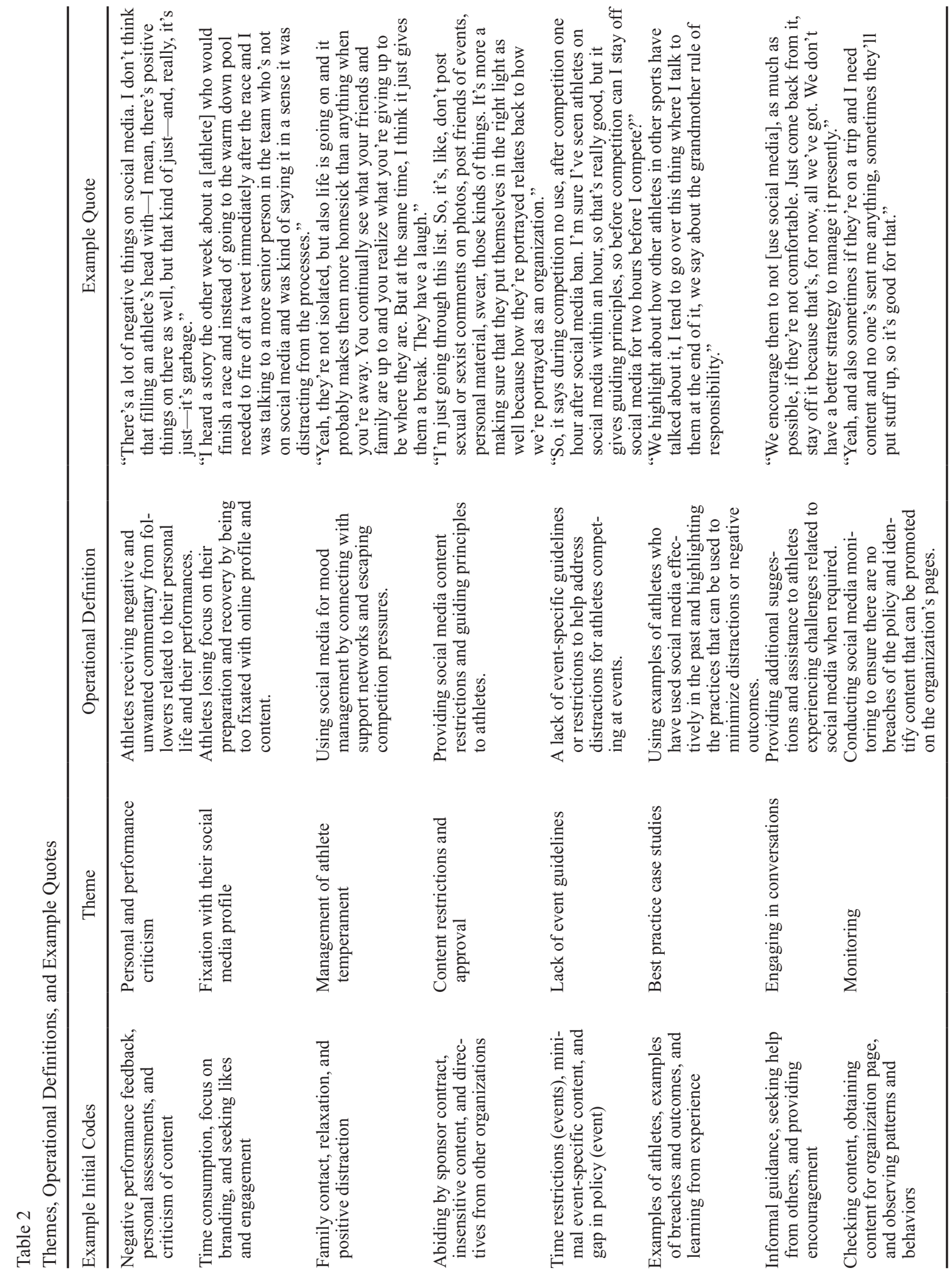


social media profile, management of athlete temperament, content restrictions and approval, lack of event guidelines, best practice case studies, engaging in conversations, and monitoring.

Peer debriefing with the remaining members of the research team was conducted to minimize bias (Morrow, 2005). Peer debriefing elicited alternative interpretations and included extensive discussions about the eight themes (Lincoln \& Guba, 1985; Morrow, 2005). Several changes were made to themes based on peer debriefing discussions including redefining four themes, providing clarification of some quotations, and renaming the themes to reflect the central idea rather than the type of mechanism. For example, the theme of best practice case studies was originally named social media training. The theme was revised to reflect the key aspect of the social media training offered to athletes, given that many of the organizations did not conduct training at the time of the interviews. Member checking was also conducted to enhance the rigor of the current research (Creswell \& Miller, 2000). Participants were sent a report containing the researcher's initial interpretation and asked to comment on whether it was accurate (Creswell \& Miller, 2000). There were no requests for alterations to the report received by the research team. An overview of the codes identified from the analysis process is presented in Table 2, including examples of what initial themes were used, before the themes are detailed in the following section (phase 6).

\section{Results}

\section{Research Question 1}

The first research question sought to understand the aspects of social media sport administrators perceive to distract athletes during major sport events. Three aspects were reported: personal and performance criticisms, fixation with their social media profile, and management of athlete temperament.

Personal and Performance Criticism. The first aspect of social media use perceived to cause a distraction was personal and performance criticism. The theme was defined as athletes receiving negative and unwanted commentary from followers related to their personal life and their performances. Rose suggested that athletes using social media who see negative comments directed at them may be adversely affected for the remainder of the competition:

You know, them [social media users] telling them [athletes] that they could have done better or they're not good enough or that's a shit [competition]. You know. And then they've got the rest of the meet to go through knowing that everyone back at home is saying all this bad stuff about me [the athlete]. How am I going to keep competing?

Irene summarized why she believed negative commentary could be an issue for athletes:

When these nasty comments come through, depending on the group, some of them are very heavily affected by a little comment and some of them can easily brush it off. I think with our [group of athletes], they probably would just brush it off and go, "Whatever. You think I'm dumb. I think you are dumber." They'd be completely fine, but some of the others, personality wise, even a small comment like, "maybe you should change your jacket," or something that seems irrelevant could affect them long term.

Wayne also illustrated that although there are positive things for athletes to see on social media, the negative aspects can stand out in an athlete's mind before a competition and potentially create problems:

There's a lot of negative things on social media. I don't think that filling an athlete's head withI mean, there's positive things on there as well, but that kind of just, really, it's just garbage. Like, there's nothing really of use on social media, so why you would put yourself to looking at that hours before competition when you don't know what's going to be on there. You know, you don't know what's going to-you're going to see that's going to have some kind of negative impact, a negative aspect on yourself leading into a competition when you need to be $100 \%$ focused.

Fixation With Their Social Media Profile. The second aspect of social media use reported by administrators was fixation with their social media profile, which was defined as athletes losing focus on their preparation and recovery by being too fixated on their online profile and content. Harry 
revealed how social media could be disruptive to the processes athletes need to follow before and after a competition, including warm downs, by saying:

I heard a story the other week about a [athlete] who would finish a race and instead of going to the warm down pool needed to fire off a tweet immediately after the race and I was talking to a more senior person in the team who's not on social media and was kind of saying it in a sense it was distracting from the processes.

Nellie revealed that although her organization's athletes are very performance focused and have not experienced many issues, some athletes can get caught up in trying to find the best photos of themselves to post on their platforms:

Athletes can get caught up with ensuring they have the best photo of themselves competing for posting on their account, or constantly monitoring the [organization's] accounts to see if they feature in an image and they can get caught up with why they may not appear in a post.

Giselle also noted that some athletes may be defining themselves based on their social media popularity in terms of "likes" and "comments," which could cause issues for athletes in terms of their other priorities and their self-worth:

You've got to work out if they're doing stuff to invoke a reaction, or they're chasing likes or engagement, then that's an area for psychologists to come into. Like, if they are defining themselves through what they put up on their social media profile, then well, that's a bigger piece. . . . But it also creates this perception you need to be liked, and that's a real battle for some athletes.

Management of Athlete Temperament. The final aspect was management of athlete temperament. In contrast to the previous themes, administrators suggested that social media could also present a positive form of distraction to athletes. The theme was defined as using social media for mood management by connecting with support networks and escaping competition pressures. Nellie explained the benefits social media can bring to athletes who are competing away from home for long periods of time:
They're traveling around that world and they're away for quite long periods of time, so I think it's actually a nice way for them to be able to engage with their family and their friends to see what they're doing. And to feel connected to back at home and to feel connected to their friends and family and the sport in general.

Further, Irene highlighted that not allowing athletes to access social media at all could have adverse effects by saying:

If they need it, because it's such a part of some people's lives that they need it to relax. We don't want to be affecting them in that way. . . . It's not even about the content. It's the action of scrolling in mindless pictures, it's just what they need to calm down.

Giselle explained that athletes compete away from home for long periods of time and may start to experience homesickness and that social media facilitates interactions with family members. She also revealed that social media allows athletes to take a break from the competition and focus on something else by saying:

Yeah, they're not isolated, but also life is going on and it probably makes them more homesick than anything when you're away. You continually see what your friends and family are up to and you realize what you're giving up to be where they are. But at the same time, I think it just gives them a break. They have a laugh.

\section{Research Question 2}

In order to minimize issues related to social media distractions, administrators reported several support and management mechanisms that had the ability to communicate social media boundaries to athletes. These mechanisms addressed the second research question. Specifically, five mechanisms were identified including content restrictions and approval, lack of event guidelines, best practice case studies, engaging in conversations, and monitoring.

Content Restrictions and Approval. The first mechanism identified was content restrictions and approval. The theme was defined as providing social 
media content restrictions and guiding principles to athletes. Administrators described their need to enforce appropriate and inappropriate content guidelines in order to protect their organization's image and restrict the time athletes spend on social media during events. In terms of content restrictions, Rose stressed the importance of ensuring social media content did not breach sponsorship agreements and this was passed on to athletes. She said:

So they can't, one of our major sponsors is [company] so they can't, on the team they can't just go around wearing other stuff, they can't write posts wearing [conflicting company] so they're very aware of what they can't post in that area. They know that they can't annoy the sponsors because they're the ones that pay them really.

Wayne highlighted a range of content restrictions that ultimately were used to protect the image of the organization and the athletes. He described what these restrictions entailed:

I'm just going through this list. So it's, like, don't post sexual or sexist comments on photos, post friends of events, personal material, swear, those kinds of things. It's more a making sure that they put themselves in the right light as well because how they're portrayed relates back to how we're portrayed as an organization.

Some participants reported receiving guidelines from National Olympic Committees (NOCs) prior to a mega-event such as the Olympic or Commonwealth Games. Administrators were required to ensure athletes received approval for their social media content before making it public. This was described in more detail by Irene:

For anything that's with the Australian team we actually get given a policy. For the Commonwealth Games, Commonwealth Games Australia send all of us a policy, and they go, "This is for your athletes. If they breach those then we come to you for an explanation." With the Olympics, the Australian Olympic team sends us their policy. Their policy is basically anything the athletes want to publish must go through them for approval first, including personal pages.

Lack of Event Guidelines. The second theme was lack of event guidelines. The theme was defined as a lack of event-specific guidelines or restrictions to help address distractions for athletes competing at events. Only one administrator revealed that eventspecific restrictions were utilized. Wayne described specific boundaries athletes are required to follow during events in addition to the other guiding principles:

So, it says during competition no use, after competition one hour after social media ban. I'm sure I've seen athletes on social media within an hour, so that's really good, but it gives guiding principles, so before competition can I stay off social media for two hours before I compete.

Meanwhile, Rose highlighted the lack of event restrictions her organization had in place. She revealed that restrictions solely focused on social media content and protecting the organization saying, "we've got a social media policy, and it's on the [organization] website. It doesn't say when they can use it, but it says they can't post certain things on social media. Whether that's derogatory towards [organization], or inappropriate content."

Harry revealed his organization did not have specific event guidelines for athletes by saying "I had a chat to our CEO more about this to try and find out whether there are limitations either side of events and there's nothing. We actually don't have anything formalized." Harry further explained the reasoning behind having a lack of event restrictions:

\footnotetext{
We want them on it, we want them engaging and the matches can be quite short. Like they can be on and off court in half an hour, so we want them kind of promoting the game before going on and then post-match sharing as much as they can see. It's a hard. It's a real hard one for us in terms of restrictions because we don't really want to place any on athletes, but we are aware obviously that it can be a distraction.
}

Giselle noted that her organization did not have specific written restrictions for events, and instead opted to link social media use to team values by saying, "we linked social media use back to what we agreed the desirable behaviors and culture of that of the team."

Best Practice Case Studies. The third mechanism highlighted by NSOs was best practice case 
studies. The theme was defined as using examples of athletes who have used social media effectively in the past and highlighting the practices that can be used to minimize distractions or negative outcomes. The key focus of this mechanism was drawing on examples of what has worked and what has not worked in the past for other athletes. Not all organizations had implemented training at the time of interviews. However, Nellie explained how best practice case studies are incorporated in her social media presentations:

Before we go into World Cups, probably, so normally somewhere between two, two and a half weeks out we'll have a conversation with them, just to remind them to make a plan before they go into competition. We highlight about how other athletes in other sports have talked about it, I tend to go over this thing where I talk to them at the end of it, we say about the grandmother rule of responsibility, don't put something up on social media that your grandmother wouldn't be proud of.

Irene acknowledged that the sport organization needed to implement social media training for athletes. She discussed her ideas to consult athletes about training first and what it might entail:

I think using the hard facts would be a good way to show the athletes, like, "This can impact your performance, and if you're working so hard to perform well, then maybe try minimizing this and it might help," because they do so many little things to do well and it's real fine detail stuff that gets in the middle.

Giselle supported the comments of other administrators by saying "I think you've got to talk about it, understand the good, the bad, the ugly, and they learn from examples." Meanwhile, Harry highlighted that providing case studies to athletes would be more beneficial when compared with other mechanisms such as written guidelines and restrictions. He explained:

But the thing that we don't do at the moment and need to do is there's not really formalized social media training as such. So, there's no sit downs with our junior players talking about what they're doing, what they could be doing better, showing them examples of social media done well compared to breaches and stuff not working.
Engaging in Conversations. The fourth theme identified was engaging in conversations. The theme was defined as providing additional suggestions and assistance to athletes experiencing challenges related to social media when required. The mechanism appeared to be a reactive strategy used to communicate boundaries when compared to other mechanisms adopted by administrators. Giselle explained that administrators would advise athletes to unfollow things that may affect them by saying, "It's like, you should just unfollow. That's the biggest advice we used to give athletes, unfollow." Irene illustrated that her organization encourages athletes to minimize their social media use if they are experiencing negative feelings:

We encourage them to not [use social media], as much as possible, if they're not comfortable. Just come back from it, stay off it because that's, for now, all we've got. We don't have a better strategy to manage it presently.

Administrators would also facilitate interactions with staff (e.g., sport psychologists) who were able to help athletes experiencing challenges. Wayne revealed athletes had access to sport psychologists, coaches, and the national performance director if needed:

We've got psychologists. Whether they're readily available or not at the major champs is the kind of next question. The coach is a big sounding board for most things, but I mean some don't like to get involved with the kind of psychology perspective, but at the Commonwealth Games we did have two psychologists around the village. Like, they were there to talk to when required. . . . And then [employee] — so [employee] is our national performance director, so anything else they would go to him as well if someone else wasn't around.

Rose explained that she and her colleagues would advise against using social media if the athletes were distracted by it. Ultimately, the decision was left to the individual athlete, explaining: "but there is that advice or guidance if they aren't sure what to do then we tell them it is up to them but if it's going to distract them, then it may be best to stay away."

Nellie further elaborated by providing an example of an incident where she was forced to step in 
and explain to an athlete that they do not need to engage with content posted about them online:

Before we've gone into an actual event where they've engaged unnecessarily with someone who's made a comment on a post on a [organization] page and they've gotten frustrated by it, so got engaged in it. We had a conversation with them and said you don't need to engage with that. You don't need to worry about it, don't get caught up in it, you've got bigger fish to fry kind of thing.

Monitoring. The final theme was monitoring, which was defined as conducting social media monitoring to ensure there are no breaches of the policy and identify content that can be promoted on the organization's pages. Monitoring was primarily conducted to ensure athletes were not breaching the organization's social media policy, rather than managing or addressing distractions. Irene revealed she monitors athlete social media to enforce the organization's policy: "Because it is pretty much like a, 'be respectful. You're representing the organization,' it's been quite simple. You can decide very quickly whether that's okay or that's not okay."

Social media monitoring also provided organizations with the ability to share content on their own pages and accounts. Nancy highlighted this by saying, "Yeah, and also sometimes if they're on a trip and I need content and no one's sent me anything, sometimes they'll put stuff up, so it's good for that." Giselle discussed an additional reason for monitoring athlete social media pages, although this method was not mentioned by the other administrators. Specifically, Giselle suggested monitoring social media allowed organizations to see any changes in athlete behavior and observe their well-being:

So you can sort of, at times, like yeah, I think it's important to monitor, to watch. Like you wouldn't see them at training, like if you come in every day and you're happy and you're go-lucky, and then all of a sudden one day you walk in and you're dark and moody, like you will talk to them. So, social media's no different.

Harry revealed he also monitored athlete social media accounts to source content for sharing purposes. He also provided an in-depth account on how monitoring was conducted:
It's literally like using, say, with Twitter, I've got just columns set up on tweet deck that will have our athletes in them and overseas athletes so I can keep across who's posting what. Facebook is a hard one because it's so big. Twitter I can keep more of a tight look on, as to what's happening and it's more for me, it's looking at who's doing what so we can share it rather than who's doing what so we can pull them into line. It's more trying to promote the good stuff they're doing on Twitter. Instagram's a hard one the education around that as well. I think needs to be around tagging the national body as often as possible in posts.

\section{Discussion}

The current research utilized semistructured interviews with sport administrators to examine the aspects of social media use that these individuals perceive to be distracting as well as what support and management mechanisms are utilized to address such concerns. Specifically, two research questions were advanced. The first research question asked: what aspects of social media (if any) do sport administrators perceive to distract athletes during major sport events? Three themes were uncovered including personal and performance criticism, fixation with their social media profile, and management of athlete temperament.

Receiving personal and performance criticism was an aspect that was suggested to distract athletes. Researchers have examined the content of negative commentary directed at athletes via social media (Litchfield et al., 2016, 2018; Sanderson \& Truax, 2014). The current research identified that these criticisms could distract athletes and have performance implications. Athletes may experience difficulties competing after reading criticisms of they themselves as these comments and messages may facilitate undesirable feelings (Hayes et al., 2020). David et al. (2018) suggested that criticism can distract athletes during training, and the current research extends this finding as sport administrators indicated personal and performance criticisms were impactful during a competition, which highlights the importance for sport administrators to address these concerns.

Next, sport administrators proposed that social media can cause athletes to be fixated with their social media profile resulting in a loss of focus on their preparation and recovery. This finding could 
have important performance implications for athletes and NSOs as sport psychology literature has established that focus is paramount to better performance (Gould et al., 1999). Further, administrators indicated that athletes who extend their social media use into the night can also disrupt others around them. The finding could be explained by the fear of missing out sentiment identified by Taylor et al. (2016) whereby athletes want to keep updated on what their friends are doing. Athletes may also be attempting to capitalize on the benefits social media afford such as updating their friends, family, and fans who may be in different locations to their competition (e.g., Hayes et al., 2019). Pulido et al. (2017) suggested that communication boundaries could impact and decrease the amount of time spent on social media and the type of content athletes promote. The findings of the current research provide additional evidence that communication boundaries could be effective in addressing social media distractions.

In contrast to the previous two themes, administrators acknowledged social media provided an avenue for athletes to manage their temperament by connecting with support networks and diverting their attention away from competition pressures. Researchers have demonstrated that athletes seek support from their family, friends, and coaches during key performance times (Rosenfeld et al., 1989). Further, athletes have been reported to use social media to maintain connections with their supporters, including their family and friends, during events (Hayes et al., 2019). The findings of the current research, combined with those of previous research, suggest that there is some level of agreement between athletes and administrators on social media's ability to facilitate connections between athletes and their family and friends and the benefits that could be achieved through these connections. These connections could elicit better performances for athletes as relaxation strategies are an important feature of athletes' psychological preparation for a competition or major sport event (Thomas et al., 1999; Ungerleider, 2005).

Taken together, the three themes highlight the difficulties sport organizations may have enforcing communication boundaries as not all distractions were negative. For example, it may be difficult for organizations to control or enforce strict boundaries around the use of social media (e.g., amount of time spent using social media) during events as they may jeopardize an athlete's ability to manage their moods. As a result, sport administrators highlighted five management and support mechanisms that answer the second research question that asks what communication boundaries are utilized by NSOs to address (or attempt to address) social media distractions during major sport events. Content approval and time restrictions, best practice case studies, engaging in conversations, and monitoring were utilized. The mechanisms demonstrated that organizations have taken both proactive and reactive approaches to communication boundaries. However, not all mechanisms appeared to be designed to address distractions.

Few NSOs implemented specific event restrictions for athletes' use of social media. Yet, for those that had event guidelines, time limits were enforced with social media use restricted before and after athletes competed, which resonates with Pegoraro (2010), who identified organizations set time limits to address issues related to athlete social media use. It appears that Australian NSOs have not taken the steps to ban social media altogether which could be explained by positive effects athletes experience when using the platforms (e.g., management of temperament) (Hayes et al., 2020). Lending support to previous research, administrators primarily attempt to control the content athletes post on social media in order to limit the number of issues arising from inappropriate content by seeking to approve content athletes post during events (McAdow et al., 2017; Sanderson, 2011). As major sport events attract an increase in national and international media attention (Heaviside et al., 2018), administrators may be using the same content restrictions and communication boundaries to minimize the potential damage inappropriate content could cause to the organization's image and reputation during these times.

Similar to previous research, social media training appeared to be a more appealing method of managing athlete social media for NSOs (McAdow et al., 2017; Sanderson \& Browning, 2013; Sanderson, Browning, \& Schmittel, 2015). Specifically, administrators utilized best practice case studies during social media training. A couple of organizations did not conduct training at the time 
of interviews, which was attributed to a lack of resources, however best practice case studies were desired. These case studies consisted of examples of athletes who used social media inappropriately in the past to highlight best practice, aligning with previous research (e.g., Sanderson \& Browning, 2013). Using examples of previous incidents could assist administrators in communicating the boundaries and expectations around social media use for athletes during major sport events as athletes could relate to some of these examples based on their own experiences. Athletes may be able to reflect on their own practices and implement their own communication boundaries to alleviate the potential for distraction. For example, as administrators noted that athletes are impacted by personal and performance criticism, athletes may refrain from posting content of a personal or professional nature until they have completed their event and may not be as affected by such criticism.

A less formal version of social media education was provided in the form of engaging in informal conversations, which may have been used to address the lack of formal social media training for some organizations. The finding presents a relatively new support mechanism sport organizations adopt, adding to previous literature on athlete social media management (e.g., McAdow et al., 2017; Sanderson, 2011; Sanderson \& Browning, 2013; Sanderson, Browning, \& Schmittel, 2015). Providing this additional assistance can complement social media training and potentially result in a more immediate response from athletes during major sport events, as educational sessions would have been conducted prior to events, while this informal approach appeared to be more ongoing. Considering communication is a goal-oriented task (Child et al., 2009; Petronio, 1991), sport administrators engaging in informal conversations with athletes could lead to the codevelopment of communication boundaries based on the individual needs of each athlete, while also ensuring the expectations of the sport organization are met (e.g., focus on competition and performance rather than athlete branding).

Finally, monitoring of athlete social media accounts was conducted. However, most sport administrators did not appear to use monitoring to manage social media distractions among athletes (e.g., identifying athletes posting late at night before a competition). This may have been due to the focus on using monitoring to enforce the organization's social media policy. For instance, the adoption of monitoring helped to ensure that athletes do not infringe upon the organization's interest and image. The finding lends support to research conducted in intercollegiate contexts (e.g., Sanderson \& Browning, 2013), as previous research has identified similar reasons for engaging in monitoring processes. The finding highlights an opportunity for sport administrators to use the mechanism for additional purposes, such as monitoring athlete behaviors and well-being via social media. If monitoring were used to assist athletes, rather than only ensuring they are not in breach of a policy, athletes may be less inclined to feel as though their privacy is compromised (Sanderson \& Browning, 2013; Snyder, 2014). Overall, it appears there is a tendency for sport organizations to act retrospectively rather than proactively in their management of athlete social media distractions. The findings of the current research can provide an evidence base for designing and/or strengthening strategies or plans to better manage athlete social media distractions.

\section{Theoretical Implications}

The findings contribute to CPM theory in several ways. First, the current research contributes to CPM and athlete social media management efforts by examining how NSOs apply privacy management restrictions and boundaries to address a specific issue related to athlete social media use (i.e., distractions). The findings indicated that multiple mechanisms were utilized to communicate boundaries to minimize social media distractions. However, several areas for improvement are required. A number of researchers have focused their attention on how communication boundaries are used to protect an organization's image from damage that may be caused by an athlete's use of social media (e.g., McAdow et al., 2017; Sanderson, 2011).

The current research contributes to the theory contextually through the application to major sport events and how social media use is managed during these times. The findings lend support to research that examined social media policies through the lens of CPM and the notion that sport organizations 
utilize policy to restrict what athlete content is disseminated publicly to protect the image of the entities (McAdow et al., 2017; Sanderson, 2011). Yet, few NSOs provided additional social media restrictions to athletes during event times, indicating that on most occasions the same communication boundaries were used during both competition and noncompetition times. However, these boundaries did not appear to be helpful in minimizing social media distractions. In some instances, event-specific guidelines were not followed despite time restrictions in place.

According to the propositions and underpinnings of CPM, the findings suggest the boundaries between NSOs and athletes are, to an extent, being broken or there is tension over these restrictions, which may be due to the positive effects athletes can elicit through their use of social media during events. More specifically, the sixth proposition of CPM speaks to the possibility of boundary turbulence due to a breakdown in communication between the co-owners of information (Child et al., 2009). The findings of the current research suggest that there is a breakdown in communication between NSOs and athletes over event-specific boundaries, as enforcement did not appear to be a priority. Instead, administrators enforced more general social media guidelines around appropriate and inappropriate content. Content needed to be approved by administrators. Administrators reported additional mechanisms that were also used to address social media concerns during events. By utilizing multiple strategies, organizations could relieve tensions over restrictions of communication during events (McAdow et al., 2017). Yet, the findings indicated that athletes have minimal input into how these mechanisms were designed and delivered, which could result in a breakdown in communication between the two stakeholders (Child et al., 2009; Sanderson, Browning, \& Schmittel, 2015).

Further, administrators were required to enforce guidelines and restrictions from other sources such as the Australian Olympic Committee (AOC) through Rule 40.3. The fifth proposition of CPM contends that social media rules should be negotiated between stakeholders (i.e., administrators and athletes). However, in the case of the current research it appears that little to no negotiation occurred, and athletes were expected to accept restrictions during events and gain approval for their content by administrators. By neglecting negotiation with athletes, administrators could be creating boundary turbulence (Child et al., 2009; Petronio, 2002). Moreover, administrators enforcing International Olympic Committee (IOC) and AOC guidelines may be presented with additional complexities when attempting to manage athlete social media (i.e., ensuring athletes are knowledgeable on all policies).

\section{Managerial Implications}

Several implications for event organizers and sport administrators are identified. First, the findings of the current research suggest that organizations attempting to manage athlete social media during events may experience some resistance, as athletes are provided with restrictions and other resources. With athletes receiving instructions from multiple sources, sport administrators and event organizers should work together to ensure that NSO policies do not contradict IOC or AOC guidelines or vice versa.

Further, athletes are given few opportunities for input. In line with CPM, the findings of the current research suggest management mechanisms should be negotiated between both athletes and NSOs in order to achieve more positive outcomes during major sport events (Child et al., 2009; Petronio, 2002; Sanderson, 2011). For social media distractions to be alleviated, it is important for organizations to communicate boundaries effectively. In turn, this may lessen the amount of criticism directed at organizations and athletes for inappropriate social media use. Event organizers could also be included in these discussions as the negative associations with athlete social media use may also affect the image of their event. By including athletes in the development process, social media training initiatives can become mutually beneficial (Sanderson, Browning, \& Schmittel, 2015) and potentially minimize the occurrence of boundary tensions between stakeholders.

Second, event organizers could integrate content related to social media and the bullying of athletes into their public service announcements. Hudson and Hudson (2013) suggested that social media can have impacts on the evaluation and advocation 
stages of event consumers' decision journey. Therefore, event organizers may be able to address the issues of negative commentary being directed to athletes during events by appealing to their consumers to be respectful in online spaces and their engagements with athletes.

Finally, event organizers could capitalize on the finding that social media can assist in managing an athlete's temperament during events. Event organizers could implement on-site designated social media spaces for athletes into event venue design. These spaces could incorporate social media content such as videos and images that are not directly related to athletes' sports or the sport event to allow athletes to unwind and escape feelings of stress related to competing. The space could also be equipped with technology, such as wireless internet, that allows athletes to communicate with their support networks (e.g., family and friends). Researchers have suggested that social interactions are an important aspect of the event experience and can lead to increases in satisfaction (Nordvall et al., 2014; Wei et al., 2017). By incorporating these interactive social media spaces into event design, event organizers could increase athlete satisfaction during their events and add value to their experiences.

\section{Limitations}

Limitations within the current research are acknowledged. First, as the current research consisted of sport administrators working within NSOs, other administrators were not included. Although best efforts were made to interview the most appropriate person, several administrators reported that coaches and/or team managers may implement additional control measures. However, coaches and/or team managers were not interviewed in the current research. Sport administrators also reported receiving additional guidelines for athlete social media use from other governing bodies (e.g., AOC) for certain events that they were required to enforce. Further, as some of the organizations included in the current research did not conduct social media training, athletes may be presented with opportunities to attend sessions elsewhere (e.g., Olympic training camps or from government funded sport academies).
Second, only one stakeholder was approached for the current research due to the focus on sport administrators. Researchers have examined the perspectives of athletes and administrators separately and across different sample groups (e.g., Olympic athletes and intercollegiate sport organizations) (e.g., Geurin, 2017; Sanderson, Browning, \& Schmittel, 2015). Yet, as CPM dictates that privacy boundaries are communicated between and among individuals (Petronio, 2002), it is important to examine the perspectives of both sport administrators and athletes on the effectiveness of the support and management mechanisms offered.

Third, due to the exploratory design of the current research and focus on an array of variables, the long-term effectiveness of the support and management mechanisms in minimizing social media distractions was not examined. Therefore, it is difficult to determine whether the mechanisms revealed in the current research assist athletes in minimizing the distractions they experience through their social media use across multiple events and stages of their careers.

\section{Future Research}

There are several research directions that can be pursued to address the limitations of the current research and build upon the current findings. First, researchers could attempt to interview additional personnel including coaches and/or team managers to gather a more holistic picture of how athlete social media is perceived and managed during events. For instance, Gould et al. (2019) indicated that coaches have begun to emphasize setting expectations, particularly among younger athletes, around mobile phone and social media use to combat distractions. Additional stakeholders that could form part of such a study include those working within National Olympic Committees (e.g., AOC and Commonwealth Games Federation) and government funded academies of sport.

Second, future research should adopt a multistakeholder perspective to evaluate the communication boundaries between sport administrators and athletes and their assistance in minimizing social media distractions. As CPM dictates boundaries are communication among and between people, the theory provides an appropriate lens for such an 
investigation. In order to obtain these perspectives, interviews should be conducted with sport administrators and athletes and focus on the support and management mechanisms desired to address social media distractions. Preferably, both samples would come from the same organizations (e.g., athletes competing in swimming and the national swimming governing body).

Finally, researchers could engage in a longitudinal study to determine the long-term effectiveness of the support and management mechanisms in terms of minimizing distractions and encouraging appropriate social media use. Reviews of social media research have suggested longitudinal approaches be adopted (Abeza et al., 2015). Such a study could include interviewing or surveying athletes and administrators before and after several events, as longitudinal studies require at least two points of data collection at a minimum (Petersen, 1993). For example, athletes could be asked to recall the key messages from social media training sessions, and whether training influenced their social media use during events and how. A longitudinal approach could also track the evolution in training as new distractions may become apparent.

\section{Conclusion}

The current research was conducted to examine the aspects of social media that sport administrators perceive to be distracting to athletes and what support and management mechanisms are utilized to address such concerns during major sport events. The findings revealed that sport administrators have a difficult task addressing athlete social media distractions as not all are negative and impact each individual athlete differently. To minimize social media distractions, sport administrators utilized a combination of several mechanisms including content restrictions and approval, lack of event guidelines, best practice case studies, engaging in conversations, and monitoring. It is hoped that the findings of the current research can provide an evidence base for designing and/or strengthening strategies or plans to better manage athlete social media distractions at future events.

\section{ORCID}

Michelle Hayes: (D https://orcid.org/0000-0001-7542-7357 Kevin Filo: (D) https://orcid.org/0000-0001-6442-3166 Caroline Riot: (iD https://orcid.org/0000-0002-3991-7233

Andrea N. Geurin:_iD https://orcid.org/0000-0002-5259-351X

\begin{tabular}{|c|c|c|c|c|c|}
\hline Age: & $18-24$ & $25-34$ & $35-44$ & $45-54$ & $\overline{55+}$ \\
\hline $\begin{array}{l}\text { Gender: } \\
\text { Job title: }\end{array}$ & Male & Female & $\begin{array}{l}\text { Sport: } \\
\text { Years i }\end{array}$ & & \\
\hline
\end{tabular}

1. In your opinion, how should athletes use social media during major sport events?

\section{Distraction:}

2. Do you perceive social media as a distraction for athletes when competing at major sport events? Why/ Why not?

3. Have you ever experienced an incident whereby an athlete has been distracted by social media or is thinking about it too much?

4. How has social media changed the way your sport prepares athletes who are competing at major sport events?

\section{Social Media Policy:}

5. Does your sport have a social media policy to guide athletes? Why/why not?

6. What do you feel is most important about the policy?

7. Can you provide an example of having to enforce this policy? How did this unfold?

8. How is the policy communicated to athletes? (e.g., e-mail, face to face, other)

9. Can you provide an example of a time that you believe the social media policy was effective? 
10. Can you provide an example of when the social media policy was breached/violated?

11. Please detail how you/your sport responds if athletes are in breach of the policy.

\section{Social Media Education:}

12. Does your sport educate athletes on appropriate social media use? Why/why not?

13. Can you please provide an example of how you/your sport educates athletes on appropriate social media use?

14. How do you perceive social media education in terms of effectiveness (e.g., does it assist athletes in minimizing social media distractions?) Why/Why not?

15. How are educational resources communicated to athletes? (e.g., e-mail, face to face)

16. How often are athletes given the opportunity to participate in social media education?

17. Do your athletes receive social media education elsewhere? If so, where and what does it contain?

18. Are your athletes provided with social media education before a major sport event? Why/Why not?

\section{Social Media Monitoring:}

19. Do you or someone within your organization monitor your athletes' social media accounts? Why/Why not?

20. How and why is social media monitoring conducted?

\section{Final Comments:}

21. Were there any other mechanisms or strategies your organization uses? Any final comments?

\section{References}

Abeza, G., O’Reilly, N., Séguin, B., \& Nzindukiyimana, O. (2015). Social media scholarship in sport management research: A critical review. Journal of Sport Management, 29(6), 601-618. https://doi.org/10.1123/ JSM.2014-0296

Braun, V., \& Clarke, V. (2006). Using thematic analysis in psychology. Qualitative Research in Psychology, 3(2), 77-101. https://doi.org/10.1191/1478088706qp063oa

Braun, V., Clarke, V., \& Weate, P. (2016). Using thematic analysis in sport and exercise research. In B. Smith \& A. Sparkes (Eds.), Routledge handbook of qualitative research in sport and exercise (pp. 191-205). Taylor \& Francis.

Burgoon, J. K. (1993). Interpersonal expectations, expectancy violations, and emotional communication. Journal of Language and Social Psychology, 12(1-2), 30-48. https://doi.org/10.1177/0261927X93121003

Child, J. T., Pearson, J. C., \& Petronio, S. (2009). Blogging, communication, and privacy management: Development of blogging privacy management measure. Journal of American Society for Information Science and Technology, 60, 2079-2094. https://doi.org/10.1002/asi.21122

Creswell, J. W., \& Miller, D. L. (2000). Determining validity in qualitative inquiry. Theory into Practice, 39(3), 124-130. https://doi.org/10.1207/s15430421tip3903_2

David, J. L., Powless, M. D., Hyman, J. E., Purnell, D. M., Steinfeldt, J. A., \& Fisher, S. (2018). College student athletes and social media: The psychological impacts of Twitter use. International Journal of Sport Communication, 11(2), 163-186. https://doi.org/10.1123/ijsc. 2018-0044
Encel, K., Mesagno, C., \& Brown, H. (2017). Facebook use and its relationship with sport anxiety. Journal of Sports Sciences, 35(8), 756-761. http://doi.org/10.1080/026404 14.2016.1186817

Entman, R. M. (1993). Framing: Toward clarification of a fractured paradigm. Journal of Communication, 43(4), 51-58. https://doi.org/10.1111/j.1460-2466.1993.tb01304.x

Etikan, I., Musa, S. A., \& Alkassim, R. S. (2016). Comparison of convenience sampling and purposive sampling. American Journal of Theoretical and Applied Statistics, 5(1), 1-4. https://doi.org/10.11648/j.ajtas.20160501.11

Farmer, P., \& Arnaudon, S. (1996). Australian sport policy. In L. Chalip, A. Johnson, \& L. Stachura (Eds.), National sport policies: An international handbook (pp. 1-22). Greenwood Press.

Farrington, N., Hall, L., Kilvington, D., Price, J., \& Saeed, A. (2014). Sport, racism and social media. Routledge.

Fynes-Clinton, J. (2012, August 02). The rise of social media among elite athletes has reached the stage where it is damaging performances says Jane Fynes-Clinton. The Courier Mail.

Gabison, G. A. (2017). The gray problem: Should athletes be punished for their social media posts? DePaul Journal of Sports Law and Contemporary Problems, 13(1), 31. https:// heinonline.org/HOL/P?h=hein.journals/jspocpd13\&i=33

Geurin, A. N. (2017). Elite female athletes' perceptions of new media use relating to their careers: A qualitative analysis. Journal of Sport Management, 31(4), 345-359. https://doi.org/10.1123/jsm.2016-0157

Gould, D., Guinan, D., Greenleaf, C., Medbery, R., \& Peterson, K. (1999). Factors affecting Olympic performance: Perceptions of athletes and coaches from more and less 
successful teams. The Sport Psychologist, 13(4), 371394. https://doi.org/10.1123/tsp.13.4.371

Gould, D., Nalepa, J., \& Mignano, M. (2019). Coaching Generation Z athletes. Journal of Applied Sport Psychology, 32(1), 104-120. https://doi.org/10.1080/10413200. 2019.1581856

Gratton, C., \& Jones, I. (2004). Research methods for sports studies. Routledge.

Hambrick, M. E., Simmons, J. M., Greenhalgh, G. P., \& Greenwell, T. C. (2010). Understanding professional athletes' use of Twitter: A content analysis of athlete tweets. International Journal of Sport Communication, 3(4), 454-471. https://doi.org/10.1123/ijsc.3.4.454

Hayes, M., Filo, K., Geurin, A., \& Riot, C. (2020). An exploration of the distractions inherent to social media use among athletes. Sport Management Review, 23(5), 852-868. https://doi.org/10.1016/j.smr.2019.12.006

Hayes, M., Filo, K., Riot, C., \& Geurin, A. (2019). Athlete perceptions of social media benefits and challenges during major sport events. International Journal of Sport Communication, 12(4), 449-481. https://doi. org/10.1123/ijsc.2019-0026

Heaviside, H. J., Manley, A. J., Didymus, F. F., \& Backhouse, S. H. (2018). "Going for Gold": Print and digital media reports of performance expectations for Olympic and Paralympic athletes. Journal of Sports Media, 13(2), 89-118. https://doi.org/10.1353/jsm.2018.0010

Horton, J., Macve, R., \& Struyven, G. (2004). Qualitative research: Experiences in using semi-structured interviews. In C. Humphrey \& B. Lee (Eds.), The real life guide to accounting research (pp. 339-357). https://doi. org/10.1016/B978-008043972-3/50022-0

Hudson, S., \& Hudson, R. (2013). Engaging with consumers using social media: A case study of music festivals. International Journal of Event and Festival Management, 4(3), 206-223. https://doi.org/10.1108/ IJEFM-06-2013-0012

Jones, J. J., Kirschen, G. W., Kancharla, S., \& Hale, L. (2018). Association between late-night tweeting and next-day game performance among professional basketball players. Sleep Health, 5(1), 68-71. https://doi. org/10.1016/j.sleh.2018.09.005

Lincoln, Y. S., \& Guba, E. G. (1985). Naturalistic inquiry. Sage.

Litchfield, C., Kavanagh, E. J., Osborne, J., \& Jones, I. (2016). Virtual maltreatment: Sexualisation and social media abuse in sport. Psychology of Women Section Review, 18(2). http://eprints.bournemouth.ac.uk/24389/

Litchfield, C., Kavanagh, E., Osborne, J., \& Jones, I. (2018). Social media and the politics of gender, race and identity: The case of Serena Williams. European Journal for Sport and Society, 15(2), 154-170. https://doi.org/10. 1080/16138171.2018.1452870

McAdow, B., Jung, J., Lambiase, J., \& Bright, L. (2017). Penalties off the field: Exploring social media policies for student athletes at universities. The Journal of Social Media in Society, 6(2), 368-405. https://www.thejsms. org/index.php/TSMRI/article/view/258
Morrow, S. L. (2005). Quality and trustworthiness in qualitative research in counseling psychology. Journal of Counseling Psychology, 52(2), 250-260. https://doi.org/ 10.1037/0022-0167.52.2.250

Nordvall, A., Pettersson, R., Svensson, B., \& Brown, S. (2014). Designing events for social interaction. Event Management, 18(2), 127-140. http://doi.org/10.37 $27 / 15$ 2599514X13947236947383

Pegoraro, A. (2010). Look who's talking-Athletes on Twitter: A case study. International Journal of Sport Communication, 3(4), 501-514. https://doi.org/10.1123/ijsc. 3.4.501

Petersen, T. (1993). Recent advances in longitudinal methodology. Annual Review of Sociology, 19(1), 425-454. https://doi.org/10.1146/annurev.so.19.080193.002233

Petronio, S. (1991). Communication boundary management: A theoretical model of managing disclosure of private information between marital couples. Communication Theory, 1(4), 311-335. https://doi.org/10.1111/j.14682885.1991.tb00023.x

Petronio, S. (2002). Boundaries of privacy: Dialectics of disclosure. SUNY Press.

Petronio, S. (2007). Translational research endeavors and the practices of communication privacy management. Journal of Applied Communication Research, 35(3), 218-222. https://doi.org/10.1080/00909880701422443

Pulido, A. J., Yang, K. C., \& Kang, Y. (2017). Collegiate student-athletes' privacy management strategies and their impact on Twitter usage behaviors. The Journal of Social Media in Society, 6(2), 406-445.

Rice, S. M., Parker, A. G., Mawren, D., Clifton, P., Harcourt, P., Lloyd, M., Kountouris, A., Smith, B., McGorry, P. D., \& Purcell, R. (2019). Preliminary psychometric validation of a brief screening tool for athlete mental health among male elite athletes: The athlete psychological strain questionnaire. International Journal of Sport and Exercise Psychology, 18(6), 850-865. https://doi.org/10. 1080/1612197X.2019.1611900

Rosenfeld, L. B., Richman, J. M., \& Hardy, C. J. (1989). Examining social support networks among athletes: Description and relationship to stress. The Sport Psychologist, 3(1), 23-33. https://doi.org/10.1123/tsp.3.1.23

Sanderson, J. (2011). To tweet or not to tweet: Exploring Division I athletic departments' social-media policies. International Journal of Sport Communication, 4(4), 492-513. https://doi.org/10.1123/ijsc.4.4.492

Sanderson, J. (2013). Social media and sport communication: Abundant theoretical opportunities. In P. M. Pedersen (Ed.), Routledge handbook of sport communication (pp. 56-65). Routledge.

Sanderson, J., \& Browning, B. (2013). Training versus monitoring: A qualitative examination of athletic department practices regarding student-athletes and Twitter. Qualitative Research Reports in Communication, 14(1), 105111. http://dx.doi.org/10.1080/17459435.2013.835348

Sanderson, J., Browning, B., \& Schmittel, A. (2015). Education on the digital terrain: A case study exploring college athletes' perceptions of social-media training. 
International Journal of Sport Communication, 8(1), 103-124. https://doi.org/10.1123/IJSC.2014-0063

Sanderson, J., \& Kassing, J. W. (2011). Tweets and blogs. Sports media: Transformation, integration, consumption. In A. Billings (Eds.), Sports media: Transformation, integration, consumption (pp. 114-118). Routledge.

Sanderson, J., Snyder, E., Hull, D., \& Gramlich, K. (2015). Social media policies within NCAA member institutions: Evolving technology and its impact on policy. Journal of Issues in Intercollegiate Athletics, 8(5), 50-73. http:// csri-jiia.org/old/documents/publications/research_articles/2015/JIIA_2015_8_3_Policies.pdf

Sanderson, J., \& Truax, C. (2014). "I hate you man!": Exploring maladaptive parasocial interaction expressions to college athletes via Twitter. Journal of Issues in Intercollegiate Athletics, 7, 333-351. http://csri-jiia. org/old/documents/publications/research_articles/2014/ JIIA $2014 \quad 7 \quad 16 \quad 333 \quad 351$ Maladaptive.pdf

Singer, E., \& Ye, C. (2013). The use and effects of incentives in surveys. The ANNALS of the American Academy of Political and Social Science, 645(1), 112-141. https:// doi.org/10.1177/0002716212458082

Snyder, E. M. (2014). An examination of student-athlete perceptions of division I social media policies. Journal of Issues in Intercollegiate Athletics, 7, 132-160. http:// csri-jiia.org/old/documents/publications/research_articles/2014/JIIA_2014_7_07_132_160_S-A_Perceptions. pdf

Sotiriadou, P., \& De Bosscher, V. (2018). Managing highperformance sport: Introduction to past, present and future considerations. European Sport Management Quarterly, 18(1), 1-7. https://doi.org/10.1080/1618474 2.2017.1400225

Stewart, B., Nicholson, M., Smith, A., \& Westerbeek, H. (2005). Australian sport -Better by design? Routledge.

Suri, H. (2011). Purposeful sampling in qualitative research synthesis. Qualitative Research Journal, 11(2), 63-75. https://doi.org/10.3316/QRJ1102063

Taylor, L., Chrismas, B. C., Dascombe, B., Chamari, K., \& Fowler, P. M. (2016). The importance of monitoring sleep within adolescent athletes: Athletic, academic, and health considerations. Frontiers in Physiology, 7(101), 1-6. http://doi.org/10.3389/fphys.2016.00101

Thomas, P. R., Murphy, S. M., \& Hardy, L. E. W. (1999). Test of performance strategies: Development and preliminary validation of a comprehensive measure of athletes' psychological skills. Journal of Sports Sciences, 17(9), 697-711. https://doi.org/10.1080/026404199365560

Ungerleider, S. (2005). Mental training for peak performance: Top athletes reveal the mind exercises they use to excel. Rodale Inc.

Wei, W., Tracy Lu, Y., \& Hua, N. (2017). Attendees' user experience of social media technology during multiphase participation in conventions: A consumption values approach. Event Management, 21(3), 347-364. https:// doi.org/10.3727/152599517X14942648527554

Zarei, A., Holmes, K., \& Yusof, A. B. (2018). Sport event attributes influencing sport tourists' attendance at Sepak Takraw event. Event Management, 22(5), 675-691. https://doi.org/10.3727/152599518X15299559637626 